Table 2. Parasites in lion faeces.

\title{
PARASITIC INFECTION IN CAPTIVE LIONS (PANTHERA LEO) AT WAYANAD
}

\section{Reghu Ravindran ${ }^{1}$, Bindu Lakshmanan ${ }^{2}$, S. Anoop ${ }^{2}$, T.S. Rajeev ${ }^{2}$ and C.N. Dinesh ${ }^{2}$}

\author{
1,2 College of Veterinary and Animal Sciences, Pookot, Wyanad, \\ Kerala 673576, India \\ Email: 1drreghuravi@yahoo.com
}

Diseases play a great role in the loss of wildlife from both forests as well as zoological parks (Acharjyo, 1998). Wild animals harbour numerous parasites in their free-living stage, but seldom lead to harmful infection unless stressed (Gaur et al., 1979). Parasites with direct lifecycles and broad host range pose the greatest threat in mixed species exhibits (Fowler \& Miller, 1999). The loss incurred due to parasitic burden of various species of birds and mammals is common and often goes unnoticed or is little understood. Zoo animals are known to be more prone to various infections (Sharma, 1998). The present communication reports parasitic infection identified in a captive lion colony at Ramgiri Estate, Varayal, Manonthoady, Wyanad, Kerala. These animals previously used for circus, were temporarily sheltered at the estate before being shifted.

Faecal samples of wild felines, including 18 lions ( 3 males \& 15 females) and one tiger under captivity at Ramgiri Estate were collected in polythene bags for examination. They were processed for concentration by centrifugation and sedimentation technique. A drop of the sediment was examined under low power objective of light microscope. The ova were identified based on Soulsby (1982).

Results of the faecal sample examination are given in the Table 1 and 2. Out of 18 faecal samples of lion examined, three were free from any parasitic infections. Fifteen samples revealed mixed helminthic infections as indicated in the tables. Samples from females and males showed no discrimination in infections. Toxascarosis was found to be the most prevalent helminthic infection among the lions. One lion was suffering from intestinal schistosomosis caused by Schistosoma spindale. Hiregoudar (1975) examined faeces of five lions (Panthera leo) and found eggs of number of helminthic parasites including those of $S$. spindale. The occurrence of Schistosoma spindale infection in lion is reported for the first time from Kerala.

Toxascaris leonina, the species found in the small intestine of dogs and cats, was previously reported from wild felids and canids in most parts of the world (Bhatia et al., 2004). The two routes of infection include oral ingestion of embryonated eggs

\begin{tabular}{lc}
\hline Parasitic species & No. of lions in which detected \\
\hline Toxascaris & 12 \\
Toxocara & 5 \\
Strongyloides & 2 \\
Schistosoma & 1 \\
Isospora & 1 \\
\hline
\end{tabular}

or by eating rodents harbouring the second stage larvae.

The infections due to Toxocara sp. and Schistosoma spindale are of zoonotic importance. Toxocarosis in humans is caused by accidental ingestion of ova of the species and the condition is manifested as visceral larva migrans. Anantaraman (1958) demonstrated that cercaria of $S$. spindale produces dermatitis in man in India.

Treatment of the condition was suggested based on Prescott (1981) and Roberson (1984). Fenbendazole @ 10mg/kg daily orally for three consecutive days was advised for the lions and tiger with roundworm infection alone. One lion suffering from multiple parasitic infection of intestinal schistosomosis and round worms was advised a combination of fenbendazole $(10 \mathrm{mg} / \mathrm{kg})$ and praziquantel $(5 \mathrm{mg} / \mathrm{kg})$ orally at weekly intervals for three weeks. The follow up trials could not be conducted as these animals were transferred to Animal Rescue Shelter, Tirupati.

\section{REFERENCES}

Acharjyo, L.N. (1998). Importance of wildlife diseases and their control, pp 46-51. In: Wild Life and Disease in India. Asiatic Publishing House.

Anantaraman, M. (1958). Dermatitis in India caused by cercariae of Schistosoma spindale Montogomery, 1906. Indian Jourmal of Helminthology 10: 46-52.

Bhatia, B.B. (2004). , pp.170-180. Text book of Veterinary Parasitology. Kalyani Publishers, Ludhiana.

Fowler, M.E. and M.E. Miller (1999). Zoo and Wild Animal Medicine $2^{\text {nd }}$ edition. W.B. Saunders Company Philadelphia, pp. 28-29.

Gaur, S.N.S., M.S. Sethi, A.C. Tiwari and O. Prakash (1979). Prevalence of helminthic parasites in wild and zoo animals in Uttar Pradesh. Indian Journal of Animal Sciences 49: 159-161.

Hiregoudar, L.S. (1975). Spirometra and Schistosome infection among lions of Gir forests in India. Current Research 4: 134-135.

Prescott, C.W. (1981). Fenbendazole in the treatment of intestinal parasites of circus lions and tigers. Veterinary Records 109: 15-16.

Roberson, E.L. (1984). Antinematodal drugs, pp. 808-817. In: Booth, N.H. and L.E. Mcdonald (Eds.). Jones Veterinary Pharmacology and Therapeutics ( $5^{\text {th }}$ edition). Kalyani Publishers, Ludhiana.

Sharma, B.D. (1998). pp. 76-83. Wild Life and Disease in India. Asiatic Publishing House.

Soulsby, E.J.L. (1982). pp. 767-772. Helminths, Arthropods and Protozoa of Domesticated Animals. Bailliere and Tindall, London.

\section{ACKNOWLedgements}

The authors are thankful to the Associate Dean, College of Veterinary and Animal Sciences, Pookot, Wayanad for the facilities provided.

Table 1. Analysis of faecal samples of lions and tiger for parasites.

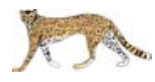

\begin{tabular}{lllll}
\hline Animal & Age group & $\begin{array}{l}\text { Number of } \\
\text { samples } \\
\text { examined }\end{array}$ & $\begin{array}{l}\text { Number of } \\
\text { samples } \\
\text { positive }\end{array}$ & Ova detected \\
\hline Lion & $\begin{array}{l}5-15 \text { years } \\
\text { Lion }\end{array}$ & 11 & 10 & $\begin{array}{l}\text { Toxascaris, Toxocara,Strongyloides, Schistosoma spindale, Oocysts of Isospora. } \\
\text { Tiger }\end{array}$ \\
\hline
\end{tabular}

(c) Zoo Outreach Organisation; www.zoosprint.org Manuscript 1438; Received 23 September 2005; Revised received 17 January 2006; Finally accepted 15 February 2006; Date of publication 21 March 2006 